\section{Warm up: Breaking Down Barriers}

\author{
Paul Hunter, ${ }^{1}$ Carolyn A Emery (D) ${ }^{1,2,3}$ Christopher Napier (D) 1,4
}

\section{LOOKING BACK}

Since the beginning of the COVID-19 pandemic, there have been a lot of words and phrases that have become part of the daily news such as 'unprecedented', 'cohort' and 'the new normal'. We also hear people speaking about how they or their families are adapting to the change. Adaptation can be defined as a process of change or evolution that allows the individual or group to cope with a situation. In sports, we see athletes do this on a continual basis. The demands of training impose physical and mental stress on the body and mind so that there are adaptations, which make the athlete stronger and more resilient. This also happens at an organisational level. Every company, government, sporting organisation, athlete and individual has had to adapt to the new reality. The year 2020 was supposed to be a full year of in-person planning, sport conferences and credentialling exams-not to mention an Olympic Summer Games. Instead, as the world abruptly shut down, Sport Physiotherapy Canada (SPC) had to pivot rapidly. We did what athletes do in sport: we analysed, planned, changed and adapted to our new reality. Though 2020 was difficult, like so many of you, we feel like we are more resilient and better equipped to face the challenges going forward.

In the Fall of 2020, the Chairpersons from all of the Canadian Physiotherapy Association (CPA) divisions met to discuss future planning and joint initiatives. While 2020 brought a pandemic to our doorstep, we also witnessed a groundswell of frustration and anger culminating in the Black Lives Matter movement. These protests were a catalyst for our society to acknowledge systemic racism, start talking about it

\footnotetext{
${ }^{1}$ Sport Physiotherapy Canada, Ottawa, Ontario, Canada ${ }^{2}$ Departments of Paediatrics and Community Health Sciences, Cumming School of Medicine, Calgary, Alberta, Canada

${ }^{3}$ Sport Injury Prevention Research Centre, Faculty of Kinesiology, University of Calgary, Calgary, Alberta, Canada

${ }^{4}$ Department of Physical Therapy, The University of British Columbia, Vancouver, British Columbia, Canada

Correspondence to Dr Christopher Napier, Department of Physical Therapy, The University of British Columbia, Vancouver, BC V6T 1Z3, Canada; chris.napier@ubc.ca
} 2021, Toronto, Canada. and make changes in our personal and professional lives. Among all of the CPA division chairs, our main focus was diversity and inclusion. There was a consensus that this is an issue that has been glossed over for too long. We must start putting our words into action.
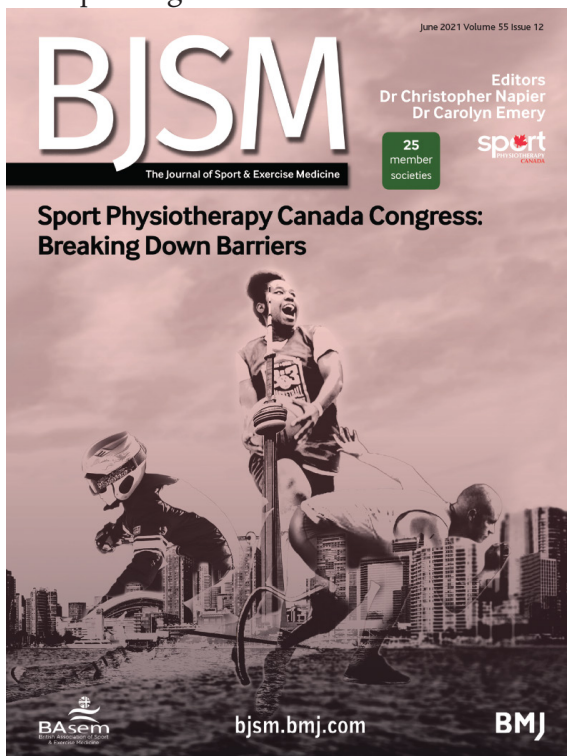

\section{LOOKING FORWARD}

Throughout 2021, the CPA has pledged to work towards the topic of IDEA-or Inclusion, Diversity, Equity and Access. At SPC, we have engaged the Canadian Centre for Diversity and Inclusion to navigate this work. A CPA advisory group populated with individuals who represent diverse lived experience and/or knowledge of physiotherapy and healthcare will also inform and advise on the actions and products of the CPA and SPC. We are also excited to be resuming our educational programme in 2021 with our biennial SPC Congress (\#SPC2021). SPC, in partnership with the International Federation of Sports Physical Therapy will aim to 'Break Down Barriers' between research and best practice in sport physiotherapy across multiple contexts. After successfully hosting the World Congress of Sports Physical Therapy in Vancouver in 2019, "Breaking Down Barriers"-\#SPC2021-has been confirmed for 15-16 October 2021 in Toronto at the Sheraton Centre Toronto Hotel (figure 1). The themes of Congress will include Injury Prevention, Concussion, Preparing for Competition, Diversity in Sport, Parasport, Musculoskeletal Injury (Return to Sport and Consequences of Injury), Workload, Recovery and Injury, and Interprofessional Collaboration.

\section{BREAKING DOWN BARRIERS}

Picking up on these themes, we are excited to bring to you the 2021 SPC Issue of BJSM. In this issue, you will find thought-provoking editorials on the barriers to translating research to clinical practice (see page 652), clinician education (see page 651), the bright side of clinicians entering the world of academia (see page 654) and the problems facing the current clinical research model (see pages 647 and 648). We also present the latest on sport injury prevention, including the Youth Running Consensus Statement (see page 305) and original research on professional rugby union injury risk (see page 676). You will also find original research on concussion injuries in National Football League players (see page 683) and a systematic review on

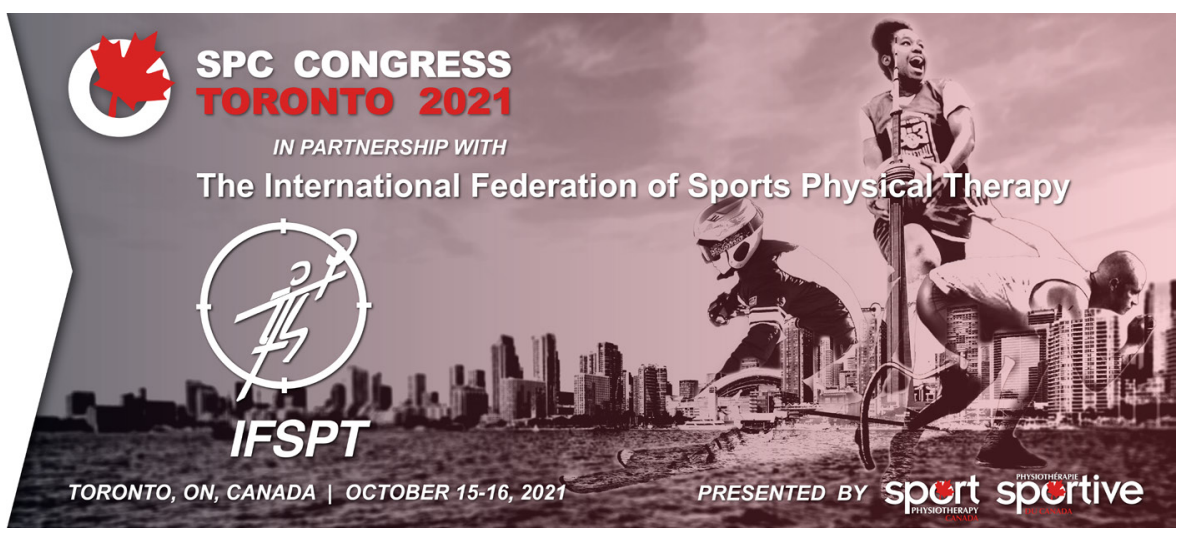

Figure 1 Sport Physiotherapy Canada Congress 2021: Breaking Down Barriers. 15-16 October 


\section{Warm up}

the risk of recurrent concussion in children and adolescents (see page 663).

These themes and more will be discussed at SPC Congress by researchers, clinician-scientists, clinicians and athletes with a national and international breadth of speakers. SPC Congress aims to bring the most up to date and relevant evidence that will inform best practice for physiotherapists working with sport participants and athletes across the lifespan and in a diversity of settings. Furthermore, panel discussions will engage athletes and clinicians to facilitate discussions that will inform future research and best practice in sport physiotherapy. We will once again highlight top abstract submissions in an abstract competition session, that is sure to engage the sport physiotherapy community. With the progress in vaccines, we are hopeful that we will again welcome the world to Canada for an international panel of speakers and sport physiotherapy content. Regardless, we have a hybrid event planned so that in-person or not, the sports physiotherapy world will be able to join in-we look forward to seeing you there!

Twitter Carolyn A Emery @CarolynAEmery and Christopher Napier @runnerphysio

Contributors PH, CAE and CN contributed equally to the writing of this paper.

Funding The authors have not declared a specific grant for this research from any funding agency in the public, commercial or not-for-profit sectors.
Competing interests None declared.

Patient consent for publication Not required.

Provenance and peer review Commissioned; internally peer reviewed.

(C) Author(s) (or their employer(s)) 2021. No commercial re-use. See rights and permissions. Published by BMJ.

\section{A Check for updates}

To cite Hunter P, Emery CA, Napier C. Br J Sports Med 2021;55:645-646.

Accepted 24 March 2021

Br J Sports Med 2021;55:645-646. doi:10.1136/bjsports-2021-104237

\section{ORCID iDs}

Carolyn A Emery http://orcid.org/0000-0002-9499-

6691

Christopher Napier http://orcid.org/0000-0002-14543546 